University of Wollongong

Research Online

Faculty of Science, Medicine and Health -

Papers: Part B

Faculty of Science, Medicine and Health

$1-1-2020$

\title{
Estimated intake and major food sources of flavonoids among Australian adolescents
}

Katherine S. Kent

University of Wollongong, kentk@uow.edu.au

Karen E. Charlton

University of Wollongong, karenc@uow.edu.au

Therese O'Sullivan

Wendy Oddy

Follow this and additional works at: https://ro.uow.edu.au/smhpapers1

\section{Publication Details Citation}

Kent, K. S., Charlton, K. E., O'Sullivan, T., \& Oddy, W. (2020). Estimated intake and major food sources of flavonoids among Australian adolescents. Faculty of Science, Medicine and Health - Papers: Part B.

Retrieved from https://ro.uow.edu.au/smhpapers1/1618

Research Online is the open access institutional repository for the University of Wollongong. For further information contact the UOW Library: research-pubs@uow.edu.au 


\title{
Estimated intake and major food sources of flavonoids among Australian adolescents
}

\author{
Abstract \\ (C) 2020, Springer-Verlag GmbH Germany, part of Springer Nature. Purpose: The consumption of dietary \\ flavonoids from plant-based foods has been related to the prevention of multiple chronic diseases. \\ However, intake data from adolescents are lacking. We aimed to characterise the intake and major \\ sources of dietary flavonoids among Australian adolescents and investigate changes during adolescence. \\ Methods: The Raine Study Gen 2 participants completed a 212-item food frequency questionnaire at age \\ 14 years and 17 years, with repeated measures for $n=883$. Items were assigned a content for six \\ flavonoid subclasses using the Phenol-Explorer database, which were summed for total flavonoid intake. \\ Daily intakes and sources of flavonoids and flavonoid-subclasses were determined, and change assessed \\ between 14 and 17 years, for males and females. Results: Major food sources of flavonoids and each \\ subclass were similar at 14 and 17 years, with fruit juice the major contributor to total flavonoid intake at \\ both time points (providing $44 \%$ and $38 \%$, respectively). Citrus flavanones (predominantly hesperitin) were \\ the major subclass at 14 years, while tea flavan-3-ols were a major subclass (predominantly procyanidin \\ dimers) at 17 years. The mean intake of total flavonoids at 14 years was $210 \pm 133 \mathrm{mg} / \mathrm{day}$, reducing by \\ $5 \%$ (10 mg/day) by 17 years. Females consumed a more flavonoid-dense diet compared to males (104.5 \\ $\pm 71.5 \mathrm{mg} / 1000 \mathrm{kcal}$ vs $80.4 \pm 50.3 \mathrm{mg} / 1000 \mathrm{kcal}$ per day; $p<0.001)$. Conclusion: This study provides a \\ comprehensive estimation of flavonoid intake and their major food sources in a sample of Australian \\ adolescents, which may be useful in the development of practical dietary recommendations.

\section{Publication Details} \\ Kent, K., Charlton, K., O'Sullivan, T. \& Oddy, W. (2020). Estimated intake and major food sources of \\ flavonoids among Australian adolescents. European Journal of Nutrition,
}


2 Katherine Kent ${ }^{* 1}$, Karen Charlton ${ }^{2,3}$, Therese O’Sullivan ${ }^{4}$, Wendy H. Oddy ${ }^{5}$

3

Key Words: Flavonoids, adolescents, dietary assessment, Raine Study Australia

*Corresponding Author

Katherine Kent, Email: Katherine.kent@utas.edu.au, Phone +61 363244053

Running Title

Flavonoid intake among Australian adolescents

ORCID ID:

Katherine Kent https://orcid.org/0000-0002-5330-7044

Karen Charlton https://orcid.org/0000-0002-8044-444X

Therese O'Sullivan https://orcid.org/0000-0003-1003-854X

Wendy H Oddy https://orcid.org/0000-0002-6119-7017

1. Centre for Rural Health, University of Tasmania, Launceston, TAS, 7250 Australia

2. School of Medicine, University of Wollongong, Wollongong, NSW, 2522, Australia

3. Illawarra Health and Medical Research Institute, Wollongong, NSW, 2522 Australia

4. School of Medical and Health Sciences, Edith Cowan University, Joondalup, WA, 6027,

5. Menzies Institute for Medical Research, University of Tasmania, Hobart, TAS, 7000 Australia

Conflict of Interest

20 None to declare 
22 We are grateful to The Raine Study participants and their families and thank The Raine Study team

23 for cohort co-ordination and data collection. We also acknowledge the NHMRC for their long term

24 contribution to funding the study over the last 30 years.

\section{Funding}

26 We would like to acknowledge the NHMRC for their long term contribution to funding the study over

27 the last 30 years, specifically the following grants for their contribution at the Gen2-14 and Gen2-17

28 timepoints: Sly et al, ID 211912; Stanley et al, ID 003209; Stanley et al, ID 353514. We would like to

29 recognise the following Institutions for providing funding for core management of the Raine Study:

30 The University of Western Australia, Curtin University, Telethon Kids Institute, Women and Infants

31 Research Foundation, Edith Cowan University, Murdoch University, The University of Notre Dame

32 Australia and Raine Medical Research Foundation.

\section{Author Contributions}

34 Conceptualization: KK, WO; Methodology: KK, WO, KC, TO; Data analysis: KK; Writing - original 35 draft preparation: KK; Writing - review and editing: KK, WO, KC, TO.

36 Acronyms list

37 CSIRO Commonwealth Scientific and Industrial Research Organisation

38 FCDB Food Composition Database

$39 \quad$ FFQ Food Frequency Questionnaire

$40 \quad$ FSANZ Food Standards Australia New Zealand

$41 \quad$ NNS National Nutrition Survey

42 NUTTAB Nutrient Tab

43 RM ANOVA repeated measures analysis of variance 


\section{Abstract}

46 Purpose The consumption of dietary flavonoids from plant-based foods has been related to the

47 prevention of multiple chronic diseases. However, intake data from adolescents is lacking. We aimed

48 to characterise the intake and major sources of dietary flavonoids among Australian adolescents and

49 investigate changes during adolescence.

50 Methods The Raine Study Gen 2 participants completed a 212 item food frequency questionnaire at age

5114 years and 17 years, with repeated measures for $n=883$. Items were assigned a content for six

52 flavonoid subclasses using the Phenol-Explorer database, which were summed for total flavonoid intake.

53 Daily intakes and sources of flavonoids and flavonoid-subclasses were determined, and change assessed

54 between 14 and 17 years, for males and females.

55 Results Major food sources of flavonoids and each subclass were similar at 14 and 17 years, with fruit

56 juice the major contributor to total flavonoid intake at both time points (providing $44 \%$ and $38 \%$

57 respectively). Citrus flavanones (predominantly hesperitin) were the major subclass at 14 years, while

58 tea flavan-3-ols were a major subclass (predominantly procyanidin dimers) at 17 years. The mean intake

59 of total flavonoids at 14 years was $210 \pm 133 \mathrm{mg} /$ day, reducing by $5 \%(10 \mathrm{mg} /$ day $)$ by 17 years. Females

60 consumed a more flavonoid-dense diet compared to males $(104.5 \pm 71.5 \mathrm{mg} / 1000 \mathrm{kcal}$ vs $80.4 \pm 50.3$

$61 \mathrm{mg} / 1000 \mathrm{kcal}$ per day; $\mathrm{p}<0.001)$.

62 Conclusion This study provides a comprehensive estimation of flavonoid intake and their major food sources in a sample of Australian adolescents, which may be useful in the development of practical

64 dietary recommendations. 
Flavonoids are a large subclass of phytochemicals, widespread across a human diet that is rich in plantbased foods. Flavonoids are non-nutritive dietary components that are categorized into six major subclasses, namely anthocyanins, flavan-3-ols, flavanones, flavones, flavonols, and isoflavones [1] (see Table 1 for Classification, structure, and example food sources of dietary flavonoids). Each subclass comprises numerous individual compounds with unique bioavailability and bioactivity.

Within plants, flavonoids act as secondary metabolites by contributing to processes that allow the plant to adapt to its environment, such as providing pigmentation, and protecting the plant and its fruit against pathogens and environmental stressors [2]. As a component of the human diet, these secondary metabolites have been shown to provide potential health benefits over basic nutritional value of the plant [3]. A growing body of observational literature (mostly in adult populations) suggests that greater intake of dietary flavonoids is associated with a reduced risk for some chronic diseases, particularly related to reduced cardiovascular risk factors [4]. While it has been recognised that the effective prevention of various chronic diseases in adulthood should start during childhood and adolescence through the management of modifiable lifestyle factors, such as diet, the influence of dietary flavonoid intake during adolescence remains under-explored [5].

Preliminary studies have reported that consumption of flavonoids during adolescence is linked with health outcomes in adulthood, including risk factors for both type 2 diabetes [6], and cardiovascular disease [7]. However, comprehensive estimations of intake of flavonoids and their major sources in children and adolescents are limited [5, 8], especially in Australian populations.

An earlier study of flavonoid consumption in the Australian population based on data from the 1995 national nutrition survey (NNS) investigated age-related variations in flavonoid intake and sources of flavonoids [9]. Flavonoid intake estimations were provided for the population from 2 years of age. Until the age of 18 years, total and subclass flavonoid intakes were stable, after which time flavonoids from tea and wine increased markedly. Since the time of the 1995 national survey, the flavonoid food composition databases (FCDB) have expanded significantly, and therefore updated assessments of 
92 flavonoid intake are required. Recent assessments of flavonoid intake in Australian populations have 93 focussed on adults [10] and older adults [11], but not adolescents.

94 Internationally, there have been some recent estimations of flavonoids and flavonoid subclasses in 95 children and adolescents. Flavonoid intakes in Spanish adolescents has been shown to be positively associated with adherence to the Mediterranean diet [12]. In a large study of European adolescents, the HELENA study identified that flavonoids are the predominant polyphenolic subclass contributing to polyphenol consumption [8]. A study of children, adolescents and adults in the UK reported that flavan3-ols were the predominant flavonoid subclass across all age groups.

Reliable estimates of usual flavonoid intake in adolescents are needed to identify common dietary practices in this age-group, which can be used in the development of practical dietary recommendations. This information is also important as the basis for assessing the potential preventive benefits of flavonoid consumption across the lifespan and may assist in the interpretation of results from intervention studies in this age-group. adolescents at 14 and 17 years of age by:

i. Identifying the major dietary sources of flavonoids and selected flavonoid subclasses at 14 years and 17 years;

ii. Estimating usual dietary intake (mg/day) of total flavonoids at 14 years and 17 years, including 
The Australian adolescents in this study were the Raine Study Gen2 participants. The Raine Study is a longitudinal pregnancy cohort originally comprising 2900 pregnant women enrolled through the public antenatal clinic at King Edward Memorial Hospital and nearby private clinics from 1989 to 1991 [13]. The resulting 2868 live-born infants have been followed up at regular intervals throughout childhood and into adolescence. The cohort has been shown to be closely representative of the Western Australian adolescent population, with no substantial differences in family structure or socioeconomic disadvantage, however participants were more likely to reside in urban areas [35] .

The present study uses cross-sectional dietary data collected between 2003 and 2005 at the 14-year follow-up (Gen2-14), and 2006 and 2009 at the 17-year follow-up (Gen2-17). Ethics committees at King Edward Memorial Hospital, Princess Margaret Hospital and Edith Cowan University approved the research, and adolescents and their parents or guardians provided their informed written consent.

At both timepoints, a 212-item semi-quantitative food frequency questionnaire (Commonwealth Scientific and Industrial Research Organization (CSIRO) FFQ) was used to assess dietary intake over the previous year [14]. The FFQ was developed by the CSIRO and was modified to include popular snacks and beverages typically eaten by adolescents. For the 17 -year cohort, six additional questions were included to determine alcohol consumption (low alcohol beer, regular beer, alcoholic soda, wine, sherry, spirits). A research nurse checked FFQs at the time of collection for any missing or potentially incorrect responses and clarified with the adolescent as required. FFQ responses were collated and analyzed by CSIRO, with data subject to double data entry, with the results checked for any intakes that appeared to be inaccurate. Estimated daily intake of foods and nutrients was determined by the CSIRO using Australian food composition data where possible, along with British Food Composition Tables, the US Department of Agriculture (USDA) food tables and manufacturers' data. [15]. The validity of the tool against 3-day food records for assessing dietary intake in the Raine Study adolescents has been previously published [16]. Data were provided in the form of consumption of food items in grams per day. From the 212 foods in the original FFQ at 14 years, 227 food variables were provided to the 
research team (as consumption in g/day) as some fruits and vegetables were split into seasonal variables

144 (i.e. both summer/winter values provided) in the later wave of the study.

\section{Source of dietary flavonoid content values}

146

Flavonoid intake variables were generated for the purpose of this study, where flavonoid content values were applied to the FFQ food items using the Phenol-Explorer database version 3.5 [17] for individual flavonoids comprising six flavonoid subclasses (anthocyanins, flavan-3-ols, flavanones, flavones, flavonols, isoflavones), which were summed for total flavonoid intake. Phenol-Explorer is a large polyphenol food composition database, providing content data on 501 polyphenols (including 271 flavonoids) for 459 foods, including values for retention factors for common cooking and processing methods. The Phenol-Explorer is a European database but is a suitable choice for this study as no comprehensive Australian flavonoid food composition database exists (except for a small, recently published anthocyanin-database with limited data available for the anthocyanin content [18]). The lack of a comprehensive Australian database is largely due to a lack of available food composition data for flavonoids in Australian foods. This database was selected as being preferred over other international polyphenol/flavonoid databases due to its comprehensive food list, the ability to sort polyphenol data according to analytical method, and the user-friendly interface.

\section{Estimation of dietary flavonoid intake}

Six subclasses were determined: flavonols, flavones, flavanones, flavan-3-ols, anthocyanins and isoflavones, and all individual flavonoids comprising these subclasses were considered if available in the food composition database. In the absence of a standardised protocol for assigning flavonoid content values to foods, the following methodological approach was followed.

A list of food items comprising the CSIRO FFQ was generated in a database specially designed for this study (Microsoft Excel 2016), to collate the flavonoid content values for each food item in mg per 100g edible weight. A search was conducted in the Phenol-Explorer database to match each food item in the FFQ with a corresponding food with flavonoid composition data [17]. Where applicable and available, retention factors were applied to the content values based on their cooking or processing methods. For 

mixed foods (e.g. muesli) a recipe from the Food Standards Australia New Zealand (FSANZ) NUTTAB 2010 Online Searchable Database was sought [19]. If the NUTTAB recipe description of the mixed food item included flavonoid containing foods (e.g. dried fruit in the muesli), a proportion contribution of each flavonoid food item was estimated using the recipe description as a guide. In the case of nutritionally similar foods being grouped together (e.g. apples, pears), mean values were generated (e.g. half of the content value is provided by apples, and half from pears).

The Phenol-Explorer database offers various options to researchers when displaying flavonoid content values for each food. The following settings were selected: (1) values expressed as individual polyphenols and (2) units as $\mathrm{mg} / 100 \mathrm{~g}$ (gram) or $\mathrm{mg} / 100 \mathrm{ml}$ for foods and beverages respectively. As a first preference, "Chromatography after hydrolysis" values were selected, and if not available, "Chromatography" values were used. This method was applied on the basis that the hydrolysed value should be a more useful and indicative value of total content (including both free aglycone and glycoside forms of each flavonoid), rather than summing the individual glycoside values (as determined by Chromatography without hydrolysis) which may be non-exhaustive for all the potential glycosides present. Normal phase HPLC values were also used as a measure of proanthocyanidins or oligomeric flavan-3-ols, also known as condensed tannins. Folin Assay values, which provide a Total Polyphenols value was not used as this is a non-specific assessment of total polyphenols, and values may be confounded by other polyphenols and nutrients in addition to flavonoids. Foods listed in the FFQ that were not in the flavonoid databases were assumed to contain no flavonoids.

Of the dietary variables provided to the research team, 108 variables were assigned a flavonoid content. Flavonoid intakes from food were measured by multiplying the consumption (g/day) for each food by its flavonoid content (per gram edible weight). Individual flavonoids from the six subclasses were summed to provide a total value for each subclass, and data for total flavonoids were calculated as the sum of these subclasses.

\section{Statistical analyses}


Dietary flavonoid and subclass daily intake was estimated for adolescents at both 14-years and 17-years.

The percentage contribution to total flavonoid and subclass intake of each food was calculated. All statistical analyses were performed using IBM SPSS Statistics version 23 (IBM Corp. Released 2015. IBM SPSS Statistics for Windows, Version 23.0. Armonk, NY: IBM Corp.). Descriptive statistics including daily mean, and median intakes of total and individual dietary flavonoids were determined, and individuals were separated into quartiles of flavonoid intake. Demographic variables were categorical and were cross-tabulated and summarized with frequencies. Chi-square test was used to assess differences in demographic variables between quartiles of intake. Dietary flavonoid densities were calculated by adjusting daily intake estimates per 1000kcal. Intakes of flavonoids and flavonoid subclasses were not normally distributed when assessed for normality using skewness and kurtosis. Examination of a histogram for each variable showed the data were positively skewed. However, the degree of positive skew was comparable at both $14 \mathrm{y}$ and $17 \mathrm{y}$, and for males and females participants, and thus, the data were not transformed for the matched analyses. Daily intakes between $14 \mathrm{y}$ and $17 \mathrm{y}$ were compared using a paired-samples t-test. Comparisons of dietary flavonoid intakes between 14 and 17 years were presented as both $\mathrm{mg} /$ day and percentage changes. Differences in daily intakes between males and females at $14 \mathrm{y}$ and $17 \mathrm{y}$ were compared using a one-way ANOVA (sex used as the factor). Repeated measures ANOVA (RM ANOVA), using sex as the between subject factor compared differences in intake of anthocyanin-rich berries, flavan-3-ol-rich tea, and flavanone-rich fruit juice at 14 years and 17 years. Significance was $\mathrm{p}<.05$.

\section{Results}

214 Dietary data were available for $n=1632(51 \%$ male) at 14 years and $n=1009$ (47\% male) at 17 years. Energy intake in $\mathrm{kcal} /$ day $($ mean $\pm \mathrm{SD}$ ) was $2312.9 \pm 723.6$ at 14 years, and $2247.1 \pm 814.6$ at 17 years. Adolescents ( $\mathrm{n}=883 ; 47 \%$ male) adolescents provided dietary data at two timepoints. Relevant

217 sociodemographic and lifestyle factors of the adolescents who provided dietary data at both timepoints $218(\mathrm{n}=883)$ are described in Table 2 according to quartiles of flavonoid intake (Table 2). 
The five major food sources of total flavonoids and each subclass at 14 and 17 years are reported in Table 3. Fruit Juice/Drink (a variable combining fresh and reconstituted fruit juices) was the major contributor to total flavonoid intake at both 14 and 17 years providing $44 \%$ and $38 \%$, respectively. Similarly, the major food sources contributing to each flavonoid subclass were comparable at 14 and 17 years (Table 3). Black tea remained the major contributor to flavan-3-ol intake at both 14 and 17 years and showed an increase of over $10 \mathrm{mg} / \mathrm{day}$ at the 17 year time point. Berries, the major contributor to anthocyanin intake, provided a similar percentage contribution at both time points, but contributed around $4 \mathrm{mg}$ /day less at 17 years when compared to 14 years, indicating a reduction in anthocyanin intake over time. Similarly, fruit juice/drink contributed $83 \%$ to flavanone intake at both 14 and 17 years but provided $85 \mathrm{mg} /$ day at 14 years and $69 \mathrm{mg} /$ day at 17 years, indicating a reduction in flavanone intake over time. Only one food at 14 years (sprouted bean shoots) and two foods (sprouted bean shoots and beer) at 17 years were identified as containing isoflavones, and therefore isoflavones contributed little to total flavonoid intake in our analysis. Pome fruits (apples and pears) and leafy greens (silver beet and spinach) were major sources of flavonols, both providing between 3-4 mg of flavonols per day at each time point.

At 17 years, the most commonly consumed alcoholic beverage was regular beer (23\% ever consumed), wine (both red and white; $15 \%$ ever consumed), low-alcoholic beer (7\% ever consumed). Examination of the contribution of alcohol to flavonoid consumption at 17 years shows that alcohol was not a major contributor to flavonoid intake, contributing $<1 \%$ of total flavonoid intake, and up to $3 \%$ of anthocyanin intake. Similarly, small contributions are seen for flavonoids $(0.8 \%)$, flavanones $(0.04 \%)$, flavones $(0.02 \%)$, isoflavones $(0.14 \%)$, and flavan-3-ols $(1.5 \%)$.

The contribution of each flavonoid subclass to overall flavonoid intake is represented in Figure 1, showing that flavanones are the predominant flavonoid subclass at 14 years, but by 17 years flavan-3ols increase to provide the same proportion as flavanones to overall flavonoid intake (around 37\%). The percentage contribution of individual flavonoid compounds to each flavonoid subclass at 14 years are displayed in Figure 2 for a) anthocyanins, b) flavonols, c) flavanones d) flavones e) flavan-3-ols and f) isoflavones. Cyanidin is the major anthocyanin (53.8\%), Quercetin is the major flavonol, Hesperitin is 
the major flavanone (64.9\%), Apigenin is the major flavone (76.4\%), Procyanidin dimers were the major flavan-3-ols (28.8\%) and Genistein is the major isoflavone (15.4\%).

Daily intake of flavonoids and subclasses at 14 years and 17 years

Individual cases with repeated measures at both time-points had similar total flavonoid intake at 14years $(210.1 \pm 133.7 \mathrm{mg} / \mathrm{d}( \pm \mathrm{SD}))$ as the total cohort $(208.4 \pm 181.4 \mathrm{mg} / \mathrm{d})$. Similarly, the subgroup with repeated measures at 17 -years had similar intake to the complete group $(199.6 \pm 141.9 \mathrm{mg} / \mathrm{d}$ vs $199.3 \pm 143.6 \mathrm{mg} / \mathrm{d}$, respectively). Therefore, those cases with repeated measures data only ( $\mathrm{n}=883$ ) were used for the remaining analysis.

The mean daily intakes of total flavonoids and subclasses in Australian adolescents, according to sex, are reported in Table 4 using raw (absolute/energy unadjusted values) values. Total flavonoid intake differed by $5.2 \%$ between the ages of 14-years and 17-years, and intake of anthocyanins was $42 \%$ lower, and intake of flavan-3-ols $26 \%$ greater at 17-years compared with 14-years (Table 4). The mean percentage difference in intake ranged from $15 \%$ and $39 \%$ between 14 and 17 years, with higher consumption seen at 14 years, with the exception of flavan-3-ols. At 14 years median intakes $\left(25^{\text {th }}\right.$, 75th percentiles) of total flavonoids was $186.7 \mathrm{mg} / \mathrm{d}(115.6,276.1)$, intake of subclasses was $17.1 \mathrm{mg} / \mathrm{d}$ $(5.5,31.5)$ for anthocyanins, $19.4 \mathrm{mg} / \mathrm{d}(12.5,30.2)$ for flavonols, $79.4 \mathrm{mg} / \mathrm{d}(30.7,150.2)$ for flavanones, $7.7 \mathrm{mg} / \mathrm{d}(3.1,12.8)$ for flavones, $42.1 \mathrm{mg} / \mathrm{d}(26.3,73.5)$ for flavan-3-ols and $0 \mathrm{mg} / \mathrm{d}(0,0.6)$ for isoflavones. At 17 years median intakes $\left(25^{\text {th }}, 75\right.$ th percentiles $)$ of total flavonoids was lower at 168.0 $\mathrm{mg} / \mathrm{d}(96.6,268.1)$, and intake of subclasses was $8.2 \mathrm{mg} / \mathrm{d}(2.6,18.2)$ for anthocyanins, $18.2 \mathrm{mg} / \mathrm{d}(11.6$, $28.5)$ for flavonols, $53.7 \mathrm{mg} / \mathrm{d}(20.8,111.7)$ for flavanones, $5.3 \mathrm{mg} / \mathrm{d}(2.2,11.4)$ for flavones, $45.4 \mathrm{mg} / \mathrm{d}$ $(26.2,81.6)$ for flavan-3-ols and $0 \mathrm{mg} / \mathrm{d}(0,0)$ for isoflavones.

Using energy adjusted values (flavonoid intake/kcal), a paired samples t-test indicated there was no significant change in total flavonoid intake $(\mathrm{p}=0.412)$ or flavonol intake $(\mathrm{p}=0.151)$ between 14 and 17 years, with a mean change of $-2.1 \%$ and $3.6 \%$, respectively (Figure 3). However, there were significant differences in the intake of the flavonoid subclasses anthocyanins, flavanones, flavones, flavan-3-ols and isoflavones (all $\mathrm{p}<0.001$ ). 
274 Comparison of the impact of sex on flavonoid intake using raw data shows that males and female mean 275 consumption of flavonoids per day is similar (within 10mg/day difference) (Table 4). However, after 276 adjustment for energy, one-way ANOVA comparing intakes between males and females at 14 years found significant sex differences for intake of total flavonoids, and all subclasses (all $\mathrm{p}<0.001$ ), except isoflavones ( $\mathrm{p}=0.541$ ) (Figure 3). A one-way ANOVA comparing intakes between males and females at 17 years showed significant sex differences for total flavonoids, flavonols, flavan-3-ols and anthocyanins (all $\mathrm{p}<0.001$ ) and isoflavones $(\mathrm{p}=0.048)$, but this was not evident for either flavanones $(\mathrm{p}=0.872)$ or flavones $(\mathrm{p}=0.105)$. Figure 3 shows the difference between male and female adolescents at 14 and 17 years for total flavonoids and subclasses/1000kcal, representing that female adolescents had more flavonoid dense diets. Pooling the data from both 14 years and 17 years to compare sex differences in flavonoid density, a one-way ANOVA showed that females overall consumed a more flavonoid-dense diet compared to males $(104.5 \pm 71.5 \mathrm{mg} / 1000 \mathrm{kcal}$ vs $80.4 \pm 50.3 \mathrm{mg} / 1000 \mathrm{kcal}$ per day; $p<0.001)$. A time and sex interaction is evident for flavonols $(\mathrm{p}<0.001)$, flavanones $(\mathrm{p}=0.015)$ and flavan-3-ols $(\mathrm{p}<0.001)$ but not for total flavonoids, anthocyanins, flavones or isoflavones. For flavonols, females had a modest increase in intake $(1.7 \pm 3.3 \mathrm{mg} /$ day $)$ and males had a modest reduction in intake $(-1.1 \pm 0.7 \mathrm{mg} /$ day $)$. Females had a considerably greater reduction in flavanones at 17 years $(-12 \pm 6.2$ $\mathrm{mg} /$ day), compared to males $(-4 \pm 0.5 \mathrm{mg} /$ day). This relates to an overall reduction in fruit juice/drink, but especially for females who consumed $52 \mathrm{~g} /$ day less of fruit juice/drink at 17 years, compared with 14 years. A significant time and sex interaction for within-subjects contrasts (RM ANOVA) is evident for flavanone-rich juice $(\mathrm{F}(1,881)=10.36, \mathrm{p}=0.001, \mathrm{n} 2$ partial=0.012). For flavan-3-ols, females had a significantly greater intake at 17 years $(14.9 \pm 33.2 \mathrm{mg}$ /day or $54.4 \%)$ in comparison to males $(1.69 \pm 7.6$ $\mathrm{mg} /$ day or $7.4 \%$ ). This corresponds with an increase of 35g/day (or a 109\% increase) in tea consumption for females, which is more than the $12.3 \mathrm{~g} /$ day increase (or $50 \%$ increase) in tea consumption for males. The results of the RM ANOVA confirmed a significant time and sex interaction for within-subjects contrasts for flavan-3-ol-rich tea $(\mathrm{F}(1,881)=10.29, \mathrm{p}=0.001, \mathrm{n} 2$ partial=0.012). A reduction 
anthocyanin-rich berries at 17 years (Figure 4a ; a significant time interaction is evident for within subjects contrasts (RM ANOVA) for the intake of berries $\mathrm{F}(1,881)=51.34, \mathrm{p}<0.001$, n2 partial $=0.055)$.

\section{Discussion}

Our study shows the major food source of flavonoids in Australian adolescents is fruit juice, and total intake of flavonoids does not appear to change significantly between 14 and 17 years. Changes in intake for flavonoid subclasses between 14 and 17 years are due to differences in consumption of flavonoidrich foods, namely a reduction in flavanone rich orange juice and anthocyanin-rich berries, and an increase in flavan-3-ol-rich tea, and that adolescent females consume a more flavonoid-dense diet in comparison to males.

The major food sources of flavonoids in adolescents are from beverages (juice, tea) and fruits, with less flavonoids attributable to vegetables. In international studies, the major food contributors to total flavonoid intake for adolescents are typically fresh fruit (predominantly oranges, apple and pear) $[8,12$, 20, 21]; chocolate and discretionary foods (including drinking chocolate) [8, 12], with smaller proportions coming from vegetable sources $[8,12,20]$. Adolescents from Asian countries show higher consumption of isoflavone-rich soy products than adolescents from Western countries [20, 22]. In most adult populations, tea is by far the major contributor to flavonoid intake $[10,11,23]$. However, the predominant food source of flavonoids in studies of adolescents is less consistent. While in our study, fruit juice/drink was the major contributor to flavonoid intake, older Australian data from the 1995 National Nutrition Survey [9] showed that the major source of flavonoids in adolescents (12-15 and 1618 year-olds) were flavan-3-ols from tea, with minimal contributions from juices. This finding, while not comparable with our findings of 14 year-olds, is more closely aligned with our estimations for 17 year-olds, in whom flavan-3-ols are the major contributor to flavonoid intake (in addition to flavanones) due to an increase in tea consumption.

We highlight a nutritional issue about flavonoid consumption predominantly coming from fruit juices. Adolescents at 14 years had mean intakes of fruit juice of 155-166g/day (Figure 4). Current populationbased recommendations for fruit juice consumption are to limit juice consumption to $125 \mathrm{ml}$ (or $1 / 2$ cup) 
of $100 \%$ fruit juice [24], and that consumption of whole fruit is preferable to fruit juice. These

327 recommendations are supported by a review which indicates an increased adiposity in overweight children is associated with higher intakes of fruit juice [25]. However, at 17 years, intakes of juice had reduced to $114 \mathrm{~g} /$ day, which falls within the recommendations, but males remained higher consumers at $150 \mathrm{~g} / \mathrm{day}$. Studies which investigate the acceptability of flavonoid-rich fruit juice interventions to improve flavonoid intake in children [26] need to consider that products of this nature may not be nutritionally acceptable for promotion to children given their high carbohydrate content, and lower nutritional properties (e.g. fibre) compared to their fresh fruit equivalents.

Our findings vary from reported consumption of flavonoids (mg/day) in other adolescent populations (Table 5). We identified six other international studies $[5-8,12,20,27]$ which conducted a focussed investigation of flavonoid intake in adolescents, with intakes ranging from $14-355 \mathrm{mg} /$ day. However, there is inconsistency regarding the inclusion and reporting of subclass intakes (Table 5), and even the specific flavonoid compounds that are included within each subclass varies. For example, whether or not proanthocyanidins are included in the analyses can largely influence reported flavan-3-ol intakes (see table 5 for flavonoids in adolescents, with flavan-3-ol values including proanthocyanidins indicated). Additionally, two studies considered flavonoid intake from fruits, vegetables and juices only, which excludes the contributions of other important dietary sources of flavonoids such as chocolate and tea. Lastly, there were different dietary assessment methods are applied in the studies (i.e. $24 \mathrm{~h}$ recalls, food diaries and FFQs) which makes comparisons difficult and the differences in reference food composition database applied, further limits the ability to generalise and compare our findings across studies [28]. It is therefore questionable whether the differences in flavonoid intake reported are attributable to differences in flavonoid intake between populations, and or attributable to differences in methodologies of the studies and availability of food composition data [18]. The differences in dietary assessment methods for estimating nutrient intake are well established [29], with FFQs often overestimating fruit and vegetable intake in comparison to $24 \mathrm{~h}$ recall or food diary methods. This has recently been explored for dietary flavonoids, where a 96-item flavonoid-specific FFQ has shown to overestimate flavonoid and subclass intake in comparison to a 4-day food record, despite being able to 
rank individuals according to intake appropriately [23]. To improve comparisons of flavonoid intake estimations it is important that literature uses more consistent methodologies, including survey tools validated for capturing foods that are significant sources of flavonoids and improvement in regionalspecific (in this case, Australia) flavonoid food composition databases [28].

The intakes of flavonoids and subclasses in adolescents in our study were also different to adult Australian populations, in that consumption was lower even after adjusting for energy, and food sources varied leading to a difference in the proportion contribution of each subclass to total flavonoid intake. A range of flavonoid intake estimations in adult populations have been published. For Australian adults, estimated intakes for total flavonoids range from $454 \mathrm{mg} /$ day (92\% flavan-3-ols) [9], to $678 \mathrm{mg} / \mathrm{day}$ (88\% flavan-3-ols) [30] and $919 \mathrm{mg} /$ day (85\% flavan-3-ols) [23] for older adults, with tea being the major contributor to flavan-3-ol intake across all studies. The most recent investigation of flavonoid intake in Australian adults reported that flavonoid intake was $626 \pm 579 \mathrm{mg} / \mathrm{d}$ in men and women, with flavan-3-ols contributing to $87 \%$ of total flavonoids [10]. These values are significantly higher than those of adolescents in our study (210 mg/day), with only $30 \%$ flavonoid intake being provided by the flavan-3-ol subclass at 14 years, and 37\% at 17 years (Figure 1). This finding of lower flavonoid intakes in adolescents compared to adults is supported by a study in European adolescents [8], in which consumption of total polyphenols ( $\sim 75 \%$ of which were flavonoids) was markedly lower than in adult populations, with differences in the major food source. The study showed that procyanidin dimers (of which chocolate is a rich food source) were a major group of flavonoids consumed by adolescents, which is supported by our findings at 17 years. In the European study, fruit and vegetable juices only contributed to $15 \%$ of total flavonoid intake, which is distinctly lower than the contribution of flavanone rich orange juice in our study (44\% and $38 \%$ at 14 and 17 years respectively). The consumption of alcohol in European adolescents was also associated with higher total intake of flavonoids, where in the current study, alcohol was not a major flavonoid source contributing $<1 \%$.

A sex difference in flavonoid intake in Australian adolescents is evident after adjusting for energy intake, with females consuming a more flavonoid-dense diet at both 14 and 17 years. Although females have shown higher intakes of flavonoids per energy unit than men [31], a sex difference in flavonoid intake 
is not always evident in adult populations, given the overwhelming contribution of tea to flavonoid intake, which is not an energy-dense food. In accordance with our results a sex difference in anthocyanin-density of children's diets has been documented [21]. In our study, the main reason for the higher flavonoid density in females compared to males may be higher consumption of tea, fruit and vegetables, or the selection of more flavonoid-dense foods, but this remains to be studied in detail. Previous research has identified that females are more likely to report fruits and vegetables as being more palatable in comparison to males, and this appeal may drive higher consumption [32].

The strengths of our study relate to the large number of adolescents who provided dietary data at two time-points during adolescence using the same dietary assessment tool, allowing analyses to determine change over time. Insights related to the consumption of flavonoids in children and adolescents are novel due to a lack of published literature in comparison to adult populations. This comprehensive analysis of flavonoid intake will allow for future research utilising the Raine study data to link flavonoid intake with health outcomes in adolescence and beyond, in particular for both cardiometabolic and cognitive outcomes. While our study contributes a focussed assessment of flavonoid intake in Australian adolescents, it is not without limitations. Although common throughout the literature, assessment of flavonoid intake by FFQs not designed specifically for measuring flavonoid intake is not ideal as often nutritionally similar food items may be grouped despite possessing different flavonoid contents. Whilst this is common practice in FFQ design to reduce the number of food items on the tool, it is less suitable for flavonoid/polyphenol research. While most fruits and vegetables in the CSIRO FFQ were recorded as individual food items, some mixed dishes were recorded (e.g. fruit salad), and although the mixed dishes provided only a minor contribution to flavonoid intake in our analyses, this was a limitation which could contribute to imprecise assessment of flavonoid intakes. Additionally, measurement error could have been introduced by survey respondents overestimating fruit and vegetable intake, which is common when using FFQs [33]. Lastly, the Raine study was undertaken in the Western Australian state of Australia, and therefore these results may not be generalisable to the wider Australian adolescent population. 
406 This study provides a comprehensive estimation of flavonoids and subclass intake and their major food

407 sources in a population based sample of Australian adolescents. Our results suggest that fruit juice is

408 the major dietary source of flavonoids during adolescence, with citrus flavanones the predominant

409 flavonoid subclass. Although flavonoid intake does not change considerably between 14 years and 17

410 years of age, flavan-3-ol-rich tea contributes a greater proportion of total flavonoid intake in older

411 adolescents. When compared with adult Australian populations, flavonoid intake was lower, and the major sources were different, with adolescents consuming more juice and less tea. Females reported consuming more flavonoid-dense diets compared with males at both time points. Our study provides the basis for future research to assess the relationship between flavonoid intake and health outcomes in an adolescent population. Additionally, our findings may be useful to support the development of practical dietary recommendations for this age-group and to inform interventions which promote the consumption of plant-based foods to increase flavonoid intakes in adolescents.

\section{References}

1. Beecher GR (2003) Overview of Dietary Flavonoids: Nomenclature, Occurrence and Intake. J Nutr 133(10):3248S-54S.

2. Dillard CJ, German JB (2000) Phytochemicals: nutraceuticals and human health. J Sci Food Agric 80(12):1744-56.

423 3. Xiao ZP, Peng ZY, Peng MJ, Yan WB, Ouyang YZ, Zhu HL (2011) Flavonoids health

424 benefits and their molecular mechanism. Mini Rev Med Chem 11(2):169-77.4.

425 4. Kim Y, Je Y (2017) Flavonoid intake and mortality from cardiovascular disease and all

426 causes: A meta-analysis of prospective cohort studies. Clin Nutr ESPEN 20:68-77.

427 5. Ziauddeen N, Rosi A, Del Rio D, Amoutzopoulos B, Nicholson S, Page P (2018) Dietary

428 intake of (poly)phenols in children and adults: cross-sectional analysis of UK National Diet and

429 Nutrition Survey Rolling Programme (2008-2014). Eur J Nutr https://doi.org/10.1007/s00394-018-

$430 \quad 1862-3$.

431 6. Penczynski KJ, Herder C, Krupp D, Rienks J, Egert S, Wudy SA (2018) Flavonoid intake

432 from fruit and vegetables during adolescence is prospectively associated with a favourable risk factor 
$434 \quad 018-1631-3$

435 7. Penczynski KJ, Remer T, Herder C, Kalhoff H, Rienks J, Markgraf DF (2018) Habitual 436 Flavonoid Intake from Fruit and Vegetables during Adolescence and Serum Lipid Levels in Early 437 Adulthood: A Prospective Analysis. Nutrients 10(4).

438 8. Wisnuwardani R, Henauw S, Androutsos O, Forsner M, Gottrand F, Huybrechts I, et al 439 (2018) Estimated dietary intake of polyphenols in European adolescents: the HELENA study. Eur J 440 Nutr 58: 2345. https://doi.org/10.1007/s00394-018-1787-x

4419 9. Johannot L, Somerset SM (2006). Age-related variations in flavonoid intake and sources in 442 the Australian population. Pub Health Nutr 9(8):1045-54.

443 10. Murphy KJ, Walker KM, Dyer KA, Bryan J. Estimation of daily intake of flavonoids and 444 major food sources in middle-aged Australian men and women. Nutr Research 61:64-81 https://doi.org/10.1016/j.nutres.2018.10.006.

446 11. Kent K, Charlton KE, Russell J, Mitchell P, Flood VM (2015) Estimation of Flavonoid Intake 447 in Older Australians: Secondary Data Analysis of the Blue Mountains Eye Study. J Nutr Gerontol $448 \quad$ Geriatr 34(4):388-98.

449 12. Bawaked RA, Schröder H, Ribas-Barba L, Cárdenas G, Peña-Quintana L, Pérez-Rodrigo C, 450 et al (2017). Dietary flavonoids of Spanish youth: intakes, sources, and association with the $451 \quad$ Mediterranean diet. PeerJ 5:e3304.

452 13. Newnham JP, Evans SF, Michael CA, Stanley FJ, Landau LI (1993) Effects of frequent 453 ultrasound during pregnancy: a randomised controlled trial. The Lancet. 342(8876):887-91.

454 14. Baghurst KI, Record SJ (1984) A Computerised Dietary Analysis System For Use With Diet 455 Diaries Or Food Frequency Questionnaires. Community Health Studies 8(1):11-8.

456 15. Lewis J, Milligan, G.C., Hunt, A (1995) NUTTAB 95: Nutrient Data Table for Use in 457 Australia. Canberra Food Standards Australia New Zealand.

458 16. Ambrosini GL, de Klerk NH, O'Sullivan TA, Beilin LJ, Oddy WH (2009) The reliability of a 459 food frequency questionnaire for use among adolescents. Eur J Clin Nutr 63:1251. 
461 Explorer: an online comprehensive database on polyphenol contents in foods. Database, doi:

$462 \quad$ 10.1093/database/bap024.

463 18. Igwe E, Neale E, Charlton KE, Morton K, Probst YC (2017). First stage development of an 464 Australian anthocyanin food composition database for dietary studies - A systematic process and its challenges. J Food Compost Anal 64:33-8. 19. Food Standards Australia New Zealand (FSANZ) (2010) NUTTAB 2010 Online Searchable Database: FSANZ [Available from http://www.foodstandards.gov.au/science/monitoringnutrients/nutrientables/nuttab/Pages/default.aspx.

20. Kim S-A, Jun S, Joung H (2015) Estimated dietary flavonoids intake of Korean adolescent: Based on the Korea National Health and Nutrition Examination Survey 2007 2012. J Nutr Health 48(6):496-506.

473 21. Drossard C, Bolzenius K, Kunz C, Kersting M (2013) Anthocyanins in the diet of children 474 and adolescents: intake, sources and trends. Eur J Nutr 52(2):667-76. intakes of dietary flavonols and flavones among female adolescents in the Suihua area of northern

477 China. Pub Health Nutr, 18(4), 632-639. doi:10.1017/S1368980014000780 questionnaire to measure flavonoid intake in older Australian adults. Nutr Dietetics 75(1):106-16. 24. National Health and Medical Research Council NHMRC (2013). Australian dietary guidelines. Canberra: NHMRC 25. Myles \& Dennison, Barbara \& Edmunds, Lynn \& H Stratton, Howard. (2006). Fruit Juice Intake Predicts Increased Adiposity Gain in Children From Low-Income Families: Weight Status-byEnvironment Interaction. Pediatrics. 118. 2066-75. 10.1542/peds.2006-1117. anthocyanin-rich juices by children and adolescents. Appetite 58(2):623-8. 
488 vegetable consumption and its relation to markers of inflammation and oxidative stress in adolescents.

489 J Am Diet Assoc 109(3):414-21.

490 28. Peterson JJ, Dwyer JT, Jacques PF, McCullough ML (2015) Improving the estimation of 491 flavonoid intake for study of health outcomes. Nutrition reviews 73(8):553-76.

492 29. Shim J-S, Oh K, Kim HC (2014) Dietary assessment methods in epidemiologic studies. 493 Epidemiol and Health 36:e2014009.

494 30. Kent K, Charlton KE, Lee S, Mond J, Russell J, Mitchell P, et al (2018) Dietary flavonoid 495 intake in older adults: how many days of dietary assessment are required and what is the impact of 496 seasonality? Nutr J. 17(1):7.

497 31. Ovaskainen M-L, Törrönen R, Koponen JM, Sinkko H, Hellström J, Reinivuo H, et al. (2008) 498 Dietary Intake and Major Food Sources of Polyphenols in Finnish Adults. J Nutr 138(3):562-6.

499 32. Bere E, Brug J, Klepp K-I. (2008) Why do boys eat less fruit and vegetables than girls? 500 Public Health Nutr 11(3):321-5.

501 33. Thompson FE SA (2001) Dietary Assessment Methodology-Chapter 1: Elseveir Inc.

502 34. Cole TJ, Flegal KM, Nicholls D, Jackson AA (2007) Body mass index cut offs to define 503 thinness in children and adolescents: international survey. BMJ 335(7612):194.

504 35. Straker L, Mountain J, Jacques A, White S, Smith A, Landau L, et al. Cohort Profile: The Western 505 Australian Pregnancy Cohort (Raine) Study-Generation 2. Int J of Epidemiology. 2017;46(5):1384-5j. 


\section{Tables}

Table 1. Classification, structure, and example food sources of 6 major dietary flavonoid subclasses

\section{Predominant}

dietary subclass

\section{Structure $^{a}$}

Rich food source

Anthocyanins

Cyanidin<smiles></smiles>

Purple/red fruits

e.g. berries

Flavonols

Quercetin<smiles>O=c1c(O)c(-c2ccc(O)c(O)c2)oc2cc(O)cc(O)c12</smiles>

Cocoa

e.g. chocolate

Flavanones

Hesperetin<smiles>COc1ccc([C@H]2CC(=O)c3c(O)cc(O)cc3O2)cc1O</smiles>

Citrus fruits

e.g. oranges

Flavones

Apigenin<smiles>O=c1cc(-c2ccc(O)cc2)oc2cc(O)cc(O)c12</smiles>

Herbs

e.g. parsley 
Isoflavones

Daidzein

OH

Soy foods

e.g. tofu

Flavan-3-ols

Catechin<smiles>Oc1cc(O)c2c(c1)O[C@H](c1ccc(O)c(O)c1)[C@H](O)C2</smiles>

Tea

${ }^{a}$ Chemical structures sourced from PhenolExplorer polyphenol database [17] 


\begin{tabular}{|c|c|c|c|c|c|c|c|c|c|c|c|c|c|c|}
\hline & & & \multicolumn{4}{|c|}{14 years } & & \multicolumn{7}{|c|}{17 years } \\
\hline & & & Q1 & Q2 & Q3 & Q4 & Total & $\mathbf{p}$ & Q1 & $\mathbf{Q 2}$ & Q3 & Q4 & Total & $\mathbf{p}$ \\
\hline \multirow{10}{*}{$\begin{array}{l}\text { Anthropometric } \\
\text { and lifestyle } \\
\text { factors }\end{array}$} & \multirow{2}{*}{$\operatorname{Sex}$} & Female & 108 & 127 & 110 & 123 & 468 & 0.175 & 122 & 121 & 109 & 116 & 468 & 0.591 \\
\hline & & Male & 113 & 94 & 111 & 97 & 415 & & 99 & 100 & 112 & 104 & 415 & \\
\hline & \multirow{4}{*}{$\begin{array}{c}\text { BMI } \\
\text { Category }^{a}\end{array}$} & Underweight & 25 & 13 & 25 & 11 & 74 & 0.064 & 3 & 6 & 6 & 4 & 19 & 0.751 \\
\hline & & Healthy weight & 129 & 137 & 124 & 135 & 525 & & 122 & 130 & 134 & 124 & 510 & \\
\hline & & Overweight & 50 & 45 & 44 & 41 & 180 & & 56 & 55 & 43 & 55 & 209 & \\
\hline & & Missing & 17 & 26 & 28 & 33 & 104 & & 40 & 30 & 38 & 37 & 145 & \\
\hline & \multirow{4}{*}{$\begin{array}{l}\text { Physical } \\
\text { activity }\end{array}$} & 4+ times per week & 49 & 64 & 68 & 72 & 253 & 0.006 & 123 & 111 & 121 & 116 & 471 & 0.081 \\
\hline & & 1-3 times per week & 131 & 123 & 114 & 95 & 463 & & 41 & 43 & 60 & 56 & 200 & \\
\hline & & Once month or less & 26 & 14 & 14 & 22 & 76 & & 42 & 51 & 34 & 38 & 165 & \\
\hline & & Missing & 15 & 20 & 25 & 31 & 91 & & 15 & 16 & 6 & 10 & 47 & \\
\hline \multirow{14}{*}{$\begin{array}{c}\text { Sociodemographic } \\
\text { factors }\end{array}$} & \multirow{7}{*}{$\begin{array}{c}\text { Maternal } \\
\text { education } \\
\text { (Highest } \\
\text { qualification) }\end{array}$} & No qualification & 57 & 28 & 45 & 36 & 166 & 0.08 & 55 & 34 & 42 & 35 & 166 & 0.236 \\
\hline & & High School & 40 & 36 & 29 & 35 & 140 & & 38 & 40 & 32 & 30 & 140 & \\
\hline & & Trade/TAFE/Diploma & 69 & 86 & 71 & 68 & 294 & & 73 & 76 & 71 & 74 & 294 & \\
\hline & & Bachelors degree & 25 & 29 & 31 & 36 & 121 & & 24 & 31 & 33 & 33 & 121 & \\
\hline & & Postgraduate degree & 15 & 26 & 24 & 19 & 84 & & 13 & 27 & 23 & 21 & 84 & \\
\hline & & Other & 10 & 13 & 13 & 17 & 53 & & 11 & 9 & 13 & 20 & 53 & \\
\hline & & Missing & 5 & 3 & 8 & 9 & 25 & & 7 & 4 & 7 & 7 & 25 & \\
\hline & \multirow{3}{*}{$\begin{array}{l}\text { Single-parent } \\
\text { family }\end{array}$} & yes & 79 & 55 & 55 & 64 & 253 & 0.112 & 78 & 52 & 69 & 68 & 267 & 0.035 \\
\hline & & no & 142 & 165 & 165 & 156 & 628 & & 128 & 153 & 146 & 143 & 570 & \\
\hline & & missing & 0 & 1 & 1 & 0 & 2 & & 15 & 16 & 6 & 9 & 46 & \\
\hline & \multirow{4}{*}{$\begin{array}{l}\text { Annual } \\
\text { family } \\
\text { income } \\
(\$ A U D)\end{array}$} & $<\$ 35,000$ & 51 & 38 & 34 & 52 & 175 & 0.118 & 34 & 24 & 34 & 19 & 111 & 0.168 \\
\hline & & $\$ 35,001-\$ 70,000$ & 87 & 77 & 81 & 66 & 311 & & 51 & 50 & 46 & 55 & 202 & \\
\hline & & $>\$ 70,000$ & 83 & 105 & 105 & 102 & 395 & & 119 & 128 & 133 & 133 & 513 & \\
\hline & & Missing/not stated & 0 & 1 & 1 & 0 & 2 & & 17 & 19 & 8 & 13 & 57 & \\
\hline
\end{tabular}

Group characteristics are presented for adolescents who recorded dietary data (FFQ) at both $14 y$ and $17 y$ ( $n=883$ ), ${ }^{a}$ Defined according to body mass index (BMI) classification groups [34], p-values derived from Chi-Square test comparing differences in demographics according to quartiles of intake at 14y and 17y. 
14 years $(n=1632)$

\begin{tabular}{|c|c|c|c|c|c|c|c|}
\hline \multirow{3}{*}{ Flavonoid Subclass } & \multirow{3}{*}{ Rank } & \multicolumn{3}{|r|}{ Average } & \multicolumn{3}{|c|}{ Average daily } \\
\hline & & Food item & $\%$ & daily intake & Food item & $\%$ & intake \\
\hline & & & & $(\mathrm{mg} / \mathrm{d})$ & & & $(\mathrm{mg} / \mathrm{d})$ \\
\hline \multirow{5}{*}{ Flavonoids Total } & 1 & Fruit Juice/Drink & 43.93 & 93.65 & Fruit Juice/Drink & 38.51 & 76.88 \\
\hline & 2 & Black Tea & 8.29 & 17.67 & Black Tea & 14.51 & 28.90 \\
\hline & 3 & Orange, Citrus Fruit & 7.25 & 15.45 & Apples, Pears & 7.22 & 14.42 \\
\hline & 4 & Apples, Pears & 7.15 & 15.24 & Orange, Citrus Fruit & 6.59 & 13.16 \\
\hline & 5 & Berries in Season & 5.17 & 11.03 & Chocolate Milk & 5.64 & 11.26 \\
\hline \multirow{5}{*}{ Anthocyanins } & 1 & Berries, in season & 46.29 & 9.99 & Berries, in season & 42.61 & 5.54 \\
\hline & 2 & Plums, in season & 24.36 & 5.26 & Grapes, in season & 23.22 & 3.02 \\
\hline & 3 & Grapes, in season & 20.74 & 4.47 & Grapes, in season & 16.11 & 2.10 \\
\hline & 4 & Fresh fruit salad & 3.97 & .86 & Fresh fruit salad & 5.80 & 0.75 \\
\hline & 5 & Olives & 2.59 & .56 & Olives & 5.59 & 0.73 \\
\hline \multirow{3}{*}{ Flavonols } & 1 & Apples, Pears & 14.52 & 3.28 & Silver beet, Spinach & 17.85 & 3.98 \\
\hline & 2 & Silver beet, Spinach & 14.39 & 3.25 & Apples, Pears & 13.92 & 3.10 \\
\hline & 3 & Onions, raw & 10.61 & 2.39 & Onions, raw & 8.75 & 1.95 \\
\hline
\end{tabular}




\begin{tabular}{|c|c|c|c|c|c|c|c|}
\hline & 4 & Onions, fried & 7.27 & 1.64 & Onions, fried & 6.13 & 1.36 \\
\hline & 5 & Homemade vegetable soups & 6.39 & 1.44 & Black Tea & 5.81 & 1.29 \\
\hline \multirow{5}{*}{ Flavanones } & 1 & Fruit Juice/Drink & 83.92 & 85.27 & Fruit Juice/Drink & 83.30 & 69.84 \\
\hline & 2 & Orange, Citrus Fruit & 15.17 & 15.42 & Orange, Citrus Fruit & 15.66 & 13.13 \\
\hline & 3 & Fresh fruit salad & 0.44 & 0.45 & Fresh fruit salad & 0.47 & 0.40 \\
\hline & 4 & Fresh tomato & 0.42 & 0.42 & Fresh tomato & 0.46 & 0.39 \\
\hline & 5 & Fried tomato & 0.02 & 0.02 & Wine & 0.02 & 0.02 \\
\hline \multirow{5}{*}{ Flavones } & 1 & Fruit Juice/Drink & 83.89 & 7.77 & Fruit Juice/Drink & 81.12 & 6.51 \\
\hline & 2 & Celery & 2.61 & 0.24 & Olives & 3.05 & 0.25 \\
\hline & 3 & Olives & 2.04 & 0.19 & Celery & 1.84 & 0.15 \\
\hline & 4 & Homemade vegetable soups & 1.66 & 0.16 & Homemade vegetable soups & 1.75 & 0.14 \\
\hline & 5 & Capsicum & 1.32 & 0.12 & Capsicum & 1.60 & 0.13 \\
\hline \multirow{2}{*}{ Isoflavones } & 1 & Sprouted bean shoots & 100 & 0.55 & Sprouted bean shoots & 99.86 & 0.35 \\
\hline & 2 & - & - & - & Beer & 0.14 & $<0.01$ \\
\hline \multirow{5}{*}{ Flavan-3-ols } & 1 & Black Tea & 29.29 & 16.88 & Black Tea & 38.34 & 27.66 \\
\hline & 2 & Chocolate milk & 21.58 & 12.43 & Apple, Pear & 15.53 & 11.21 \\
\hline & 3 & Apple, Pear & 20.55 & 11.84 & Chocolate milk & 14.05 & 10.14 \\
\hline & 4 & Plums, in season & 8.94 & 5.15 & Herbal Tea & 8.96 & 6.46 \\
\hline & 5 & Chocolate, Chocolate bars & 4.94 & 2.85 & Chocolate, Chocolate bars & 5.13 & 3.70 \\
\hline
\end{tabular}


Table 4 Daily average intake of dietary flavonoids (and subclasses; mg/day) of Australian adolescents aged 14 years in the Raine Study and percentage change intake at 17 years ( $n=883)$ using energy unadjusted values

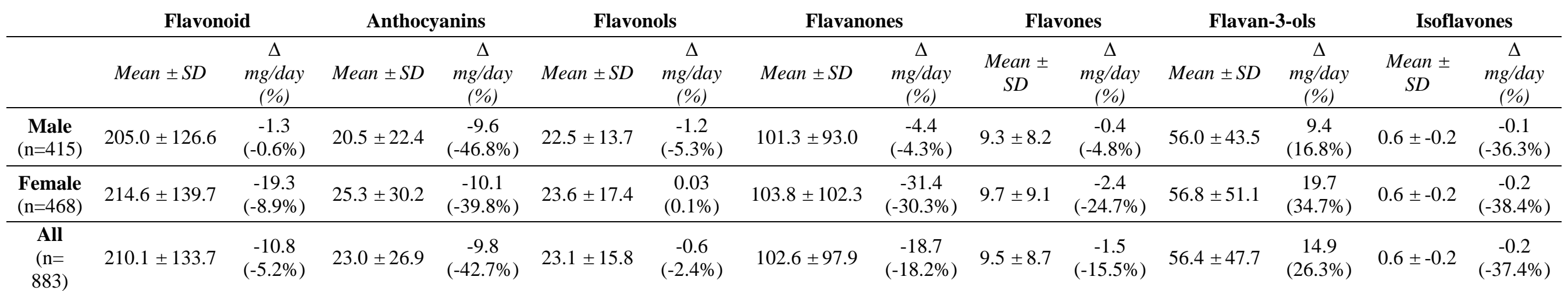

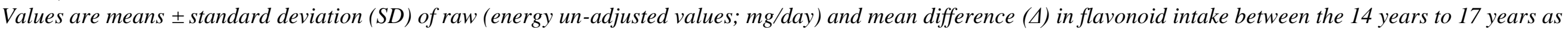

mg/day and as a percentage; intake values include both, glycosides and aglycones; Energy adjusted values are provided in Figure 3 and Table 5 


\begin{tabular}{|c|c|c|c|c|c|c|c|c|c|c|c|c|c|}
\hline Study & Country & Method & $\begin{array}{c}\text { Food } \\
\text { compositio } \\
\text { n database }\end{array}$ & $\mathbf{n}$ & Sex & $\begin{array}{c}\mathbf{A g} \\
\mathbf{e}\end{array}$ & Total Flavonoids & $\begin{array}{c}\text { Anthocyanin } \\
\text { s }\end{array}$ & $\begin{array}{c}\text { Flavonol } \\
\mathrm{s}\end{array}$ & $\begin{array}{c}\text { Flavanone } \\
\mathrm{s}\end{array}$ & $\begin{array}{c}\text { Flavone } \\
\mathbf{s}\end{array}$ & $\begin{array}{c}\text { Flavan-3- } \\
\text { ols }\end{array}$ & $\begin{array}{c}\text { Isoflavone } \\
\mathrm{s}\end{array}$ \\
\hline & & & & & & & \multicolumn{7}{|c|}{$\mathrm{mg} /$ day } \\
\hline \multirow{2}{*}{$\begin{array}{l}\text { This } \\
\text { study }^{\mathrm{a}} \\
, c\end{array}$} & \multirow{2}{*}{ Australia } & \multirow{2}{*}{ FFQ } & \multirow{2}{*}{$\begin{array}{l}\text { Phenol } \\
\text { Explorer }\end{array}$} & \multirow{2}{*}{883} & \multirow{2}{*}{$\mathrm{M}, \mathrm{F}$} & $14 y$ & $94.1 \pm 58.1$ & $10.4 \pm 11.6$ & $\begin{array}{c}10.5 \pm \\
8.8\end{array}$ & $45.7 \pm 43.8$ & $4.3 \pm 3.9$ & $25.3 \pm 22.6$ & $0.3 \pm 0.6$ \\
\hline & & & & & & $17 y$ & $92.2 \pm 68.6$ & $6.4 \pm 8.0$ & $\begin{array}{c}10.9 \pm \\
11.4\end{array}$ & $37.1 \pm 40.3$ & $3.6 \pm 3.7$ & $\begin{array}{c}33.9 \pm \\
47.2\end{array}$ & $0.2 \pm 0.5$ \\
\hline \multirow{3}{*}{$\begin{array}{l}(6, \\
7)^{\mathrm{c}, \mathrm{e}}\end{array}$} & \multirow{3}{*}{$\begin{array}{c}\text { German } \\
\mathrm{y}\end{array}$} & multiple & \multirow{3}{*}{ USDA } & \multirow{3}{*}{257} & $M$ & \multirow{3}{*}{$\begin{array}{c}9- \\
16 y\end{array}$} & $129(86 \quad 189)$ & \multirow{3}{*}{-} & \multirow{3}{*}{ - } & \multirow{3}{*}{-} & \multirow{3}{*}{ - } & \multirow{3}{*}{ - } & \multirow{3}{*}{ - } \\
\hline & & $\begin{array}{c}\text { 3-day } \\
\text { weighed }\end{array}$ & & & $\mathrm{M}$ & & $129(86,189)$ & & & & & & \\
\hline & & $\begin{array}{l}\text { food } \\
\text { records }\end{array}$ & & & $\mathrm{F}$ & & $130(88,173)$ & & & & & & \\
\hline$(12)^{d}$ & Spain & $\begin{array}{c}\text { 24-hour } \\
\text { recall }\end{array}$ & $\begin{array}{l}\text { Phenol } \\
\text { Explorer }\end{array}$ & $\begin{array}{c}3,53 \\
4 \\
\end{array}$ & $\mathrm{M}, \mathrm{F}$ & $\begin{array}{c}2- \\
24 y\end{array}$ & $70.7 \pm 84.1$ & $7.7 \pm 27.1$ & $\begin{array}{c}15.6 \pm \\
30.6\end{array}$ & $19.7 \pm 34.1$ & $2.2 \pm 9.1$ & $\begin{array}{c}25.2 \pm \\
47.1 \\
\end{array}$ & $0.1 \pm 1.4$ \\
\hline \multirow[b]{2}{*}{$(20)$} & \multirow[b]{2}{*}{ Korea } & \multirow[b]{2}{*}{ FFQ } & \multirow{2}{*}{$\begin{array}{c}\text { Flavonoid } \\
\text { database for } \\
\text { commonly } \\
\text { consumed } \\
\text { foods by } \\
\text { Koreans. }\end{array}$} & $\begin{array}{c}2,09 \\
7\end{array}$ & M & \multirow[b]{2}{*}{$\begin{array}{l}12- \\
18 y\end{array}$} & 189.4 & - & - & - & - & - & - \\
\hline & & & & $\begin{array}{c}1,80 \\
6\end{array}$ & $\mathrm{~F}$ & & 195.6 & - & - & - & - & - & - \\
\hline \multirow{2}{*}{$(27)^{\mathrm{a}}$} & \multirow{2}{*}{$\begin{array}{c}\text { United } \\
\text { States of } \\
\text { America }\end{array}$} & \multirow{2}{*}{ FFQ } & \multirow{2}{*}{ USDA } & 155 & M & \multirow{2}{*}{$\begin{array}{l}13- \\
17 y\end{array}$} & 14.2 & - & 12.71 & - & 1.52 & - & - \\
\hline & & & & 130 & $\mathrm{~F}$ & & 15.4 & - & 13.86 & - & 1.62 & - & - \\
\hline \multirow{2}{*}{$(8)^{\mathrm{c}}$} & \multirow{2}{*}{ Europe $^{b}$} & \multirow{2}{*}{$\begin{array}{c}\text { 24-hour } \\
\text { recall } \\
(\mathrm{x} 2)\end{array}$} & \multirow{2}{*}{$\begin{array}{l}\text { Phenol- } \\
\text { Explorer }\end{array}$} & 1139 & $\mathrm{M}$ & \multirow{2}{*}{$\begin{array}{l}12- \\
18 y\end{array}$} & 240 & - & - & - & - & - & - \\
\hline & & & & 1289 & $\mathrm{~F}$ & & 284 & - & - & - & - & - & - \\
\hline$(5)^{\mathrm{c}}$ & $\begin{array}{l}\text { United } \\
\text { Kingdo } \\
\text { m }\end{array}$ & $\begin{array}{l}\text { 4-day } \\
\text { food } \\
\text { records }\end{array}$ & $\begin{array}{l}\text { Phenol- } \\
\text { Explorer }\end{array}$ & 2045 & $\mathrm{M}, \mathrm{F}$ & $\begin{array}{l}11- \\
18 y\end{array}$ & $355.4 \pm 230.9$ & $32.6 \pm 61.6$ & $\begin{array}{c}20.2 \pm \\
18.4\end{array}$ & $29.8 \pm 50$ & $\begin{array}{c}23.1 \pm \\
17.6\end{array}$ & $\begin{array}{c}234.4 \pm \\
180.3\end{array}$ & $3.9 \pm 8.9$ \\
\hline
\end{tabular}


Data presented at mean $\pm S D$ (where SD was presented) or median $\left(25^{\text {th }}, 75^{\text {th }}\right.$ percentiles) ${ }^{a}$ Values adjusted for energy mg/1000kcal; - indicates missing data, ${ }^{b} A$ 10-site multicentre study including Greece, Germany, Belgium, France, Hungary, Italy, Sweden, Austria, Spain ${ }^{c}$ study included proanthocyanidins (including oligo- \& polymers) when determining flavan-3-ol content; proanthocyanidin oligo- \& polymers were omitted from the analysis when determining flavan-3-ol content values, ${ }^{e}$ intakes are determined from dietary intake of fruit, vegetables and juice only, USDA = The United States Department of Agriculture Flavonoid Database 
Figures

\section{Figure Legends}

- Figure 1 Mean percentage contribution of each flavonoid subclass to overall flavonoid intake at 14 and 17 years $(n=883)$

- Figure 2 Percentage Contribution of Individual Flavonoids to Flavonoid Subclasses at 14 years for a) anthocyanins, b) flavonols, c) flavanones d) flavones e) flavan-3-ols and f) isoflavones

- Figure 3 Mean intake (mg/day) of total flavonoids and flavonoid subclasses per 1000kcal at 14 and 17 years according to $\operatorname{sex}(n=883)$

- Figure 4 Change in mean intake of anthocyanin-rich berries (a), flavan-3-ol-rich tea $(b)$ and flavanone-rich fruit juice (c) (grams/day) at 14 and 17 years according to sex 


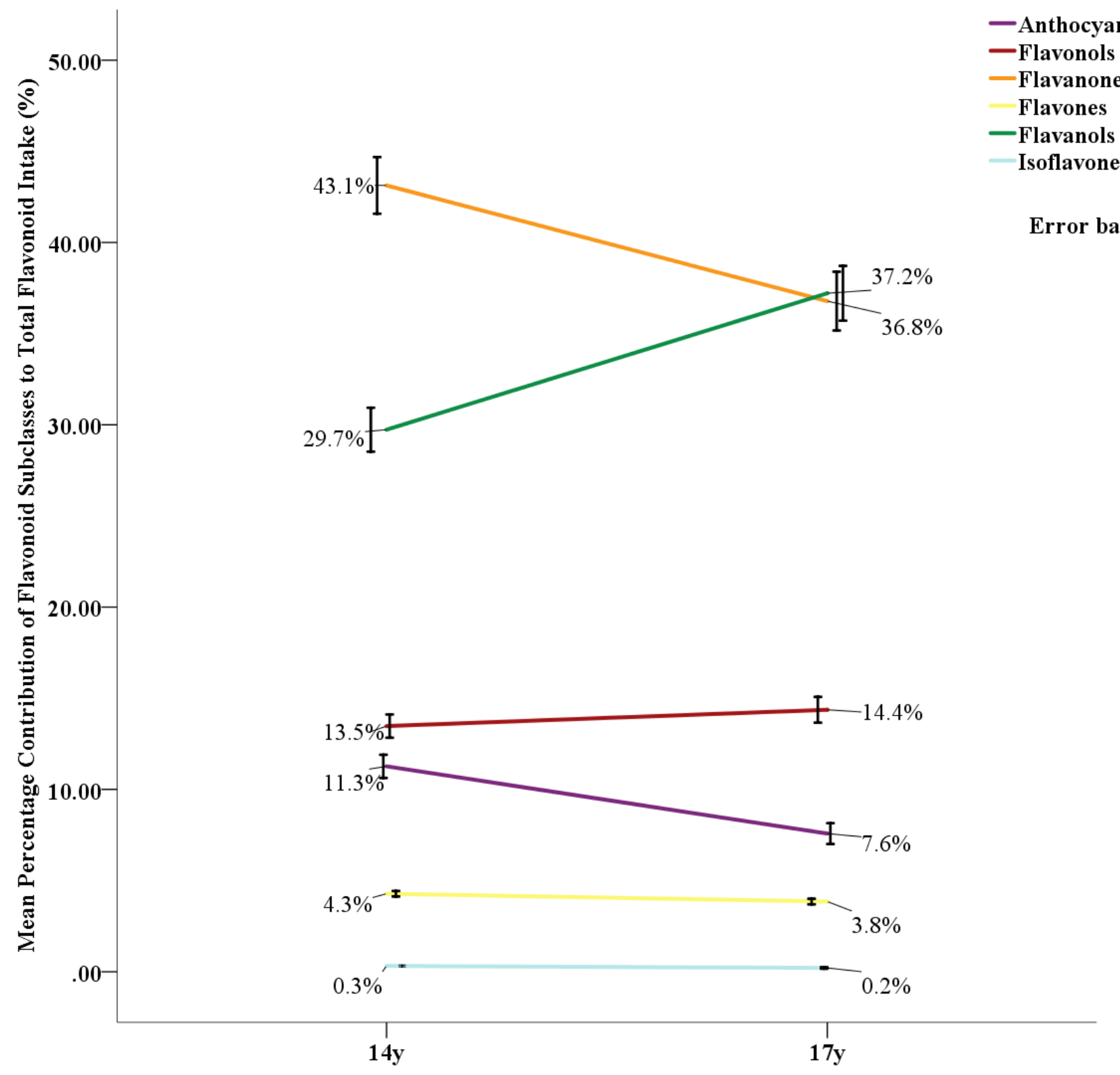

Figure 1 Mean percentage contribution of each flavonoid subclass to overall flavonoid intake at 14 and 17 years $(n=883)$ 
A) anthocyanins

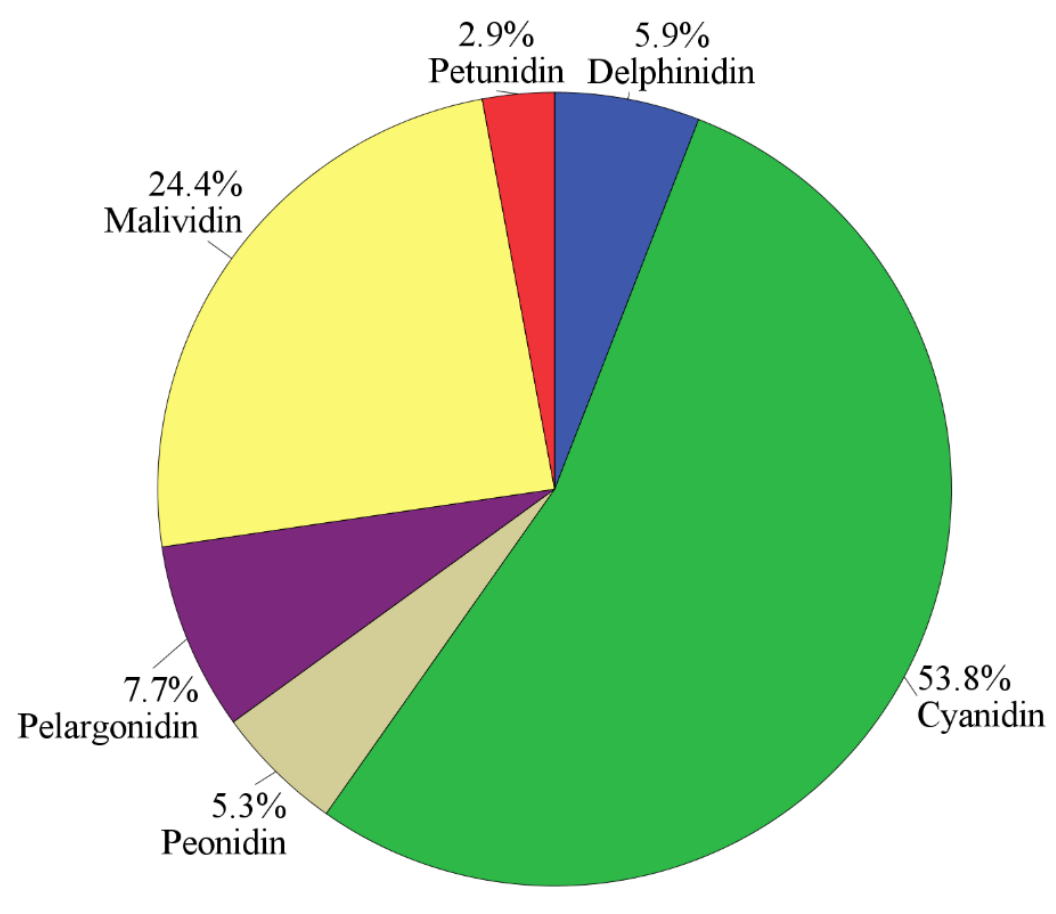

B) flavonols

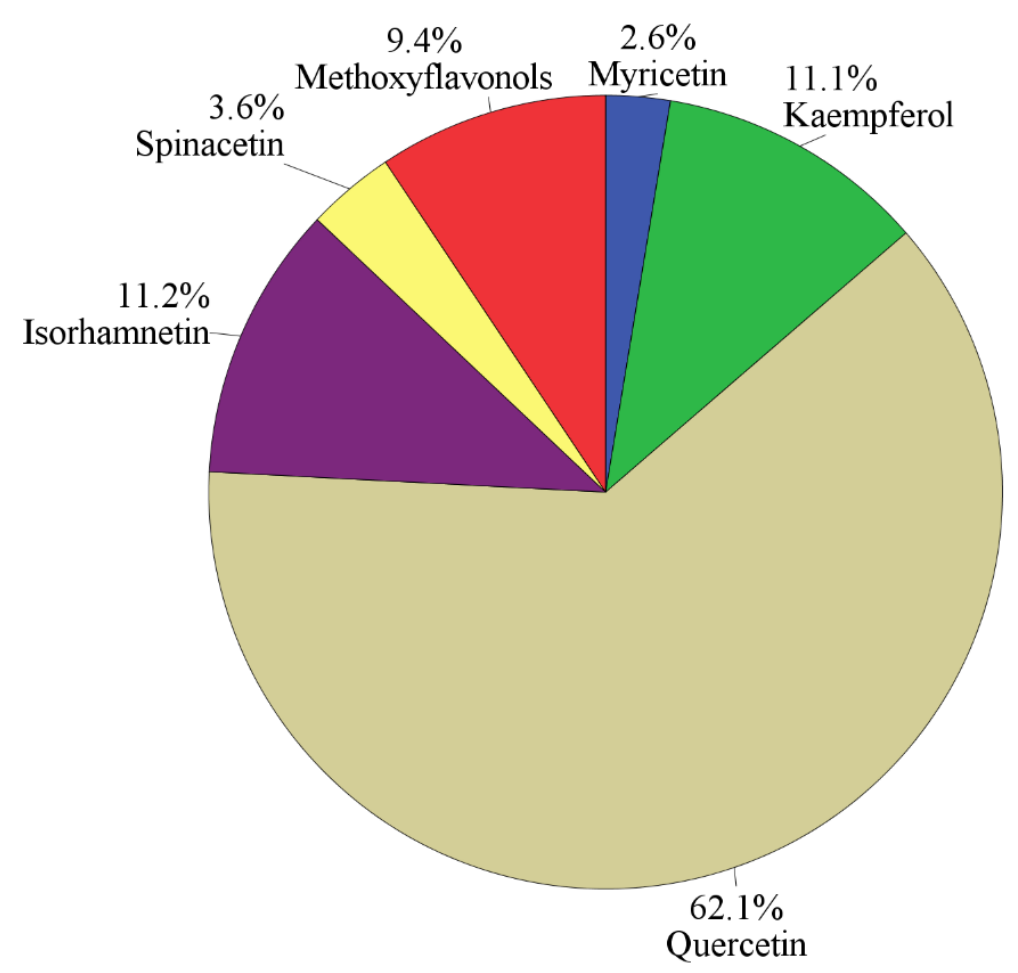




\section{C) flavanones}

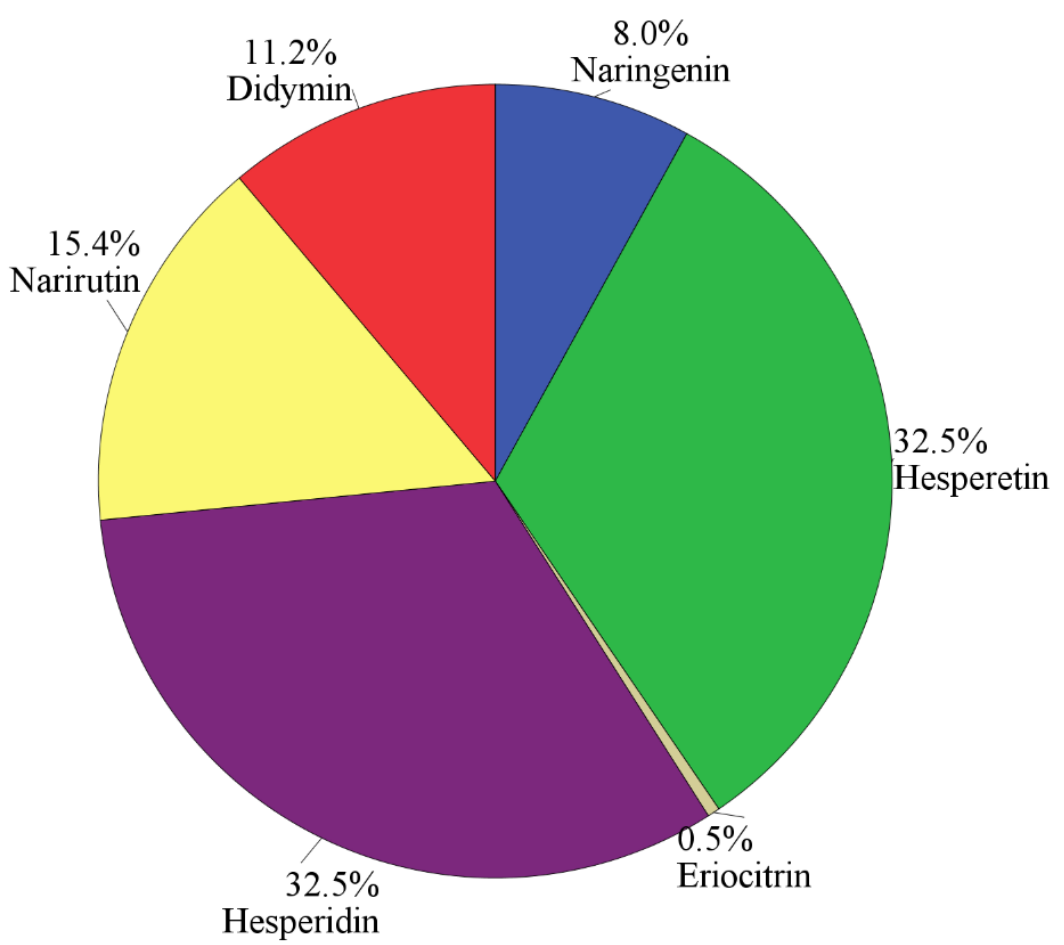

D) flavones

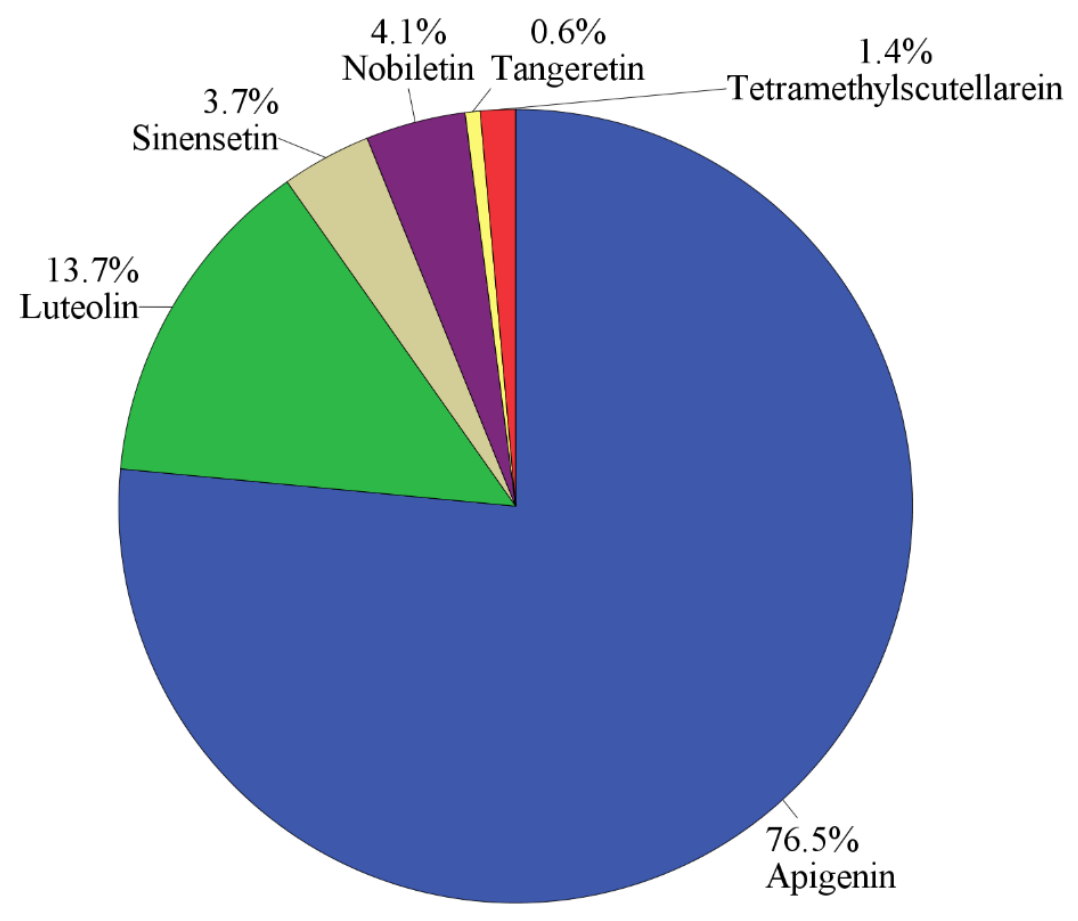


E) flavan-3-ols

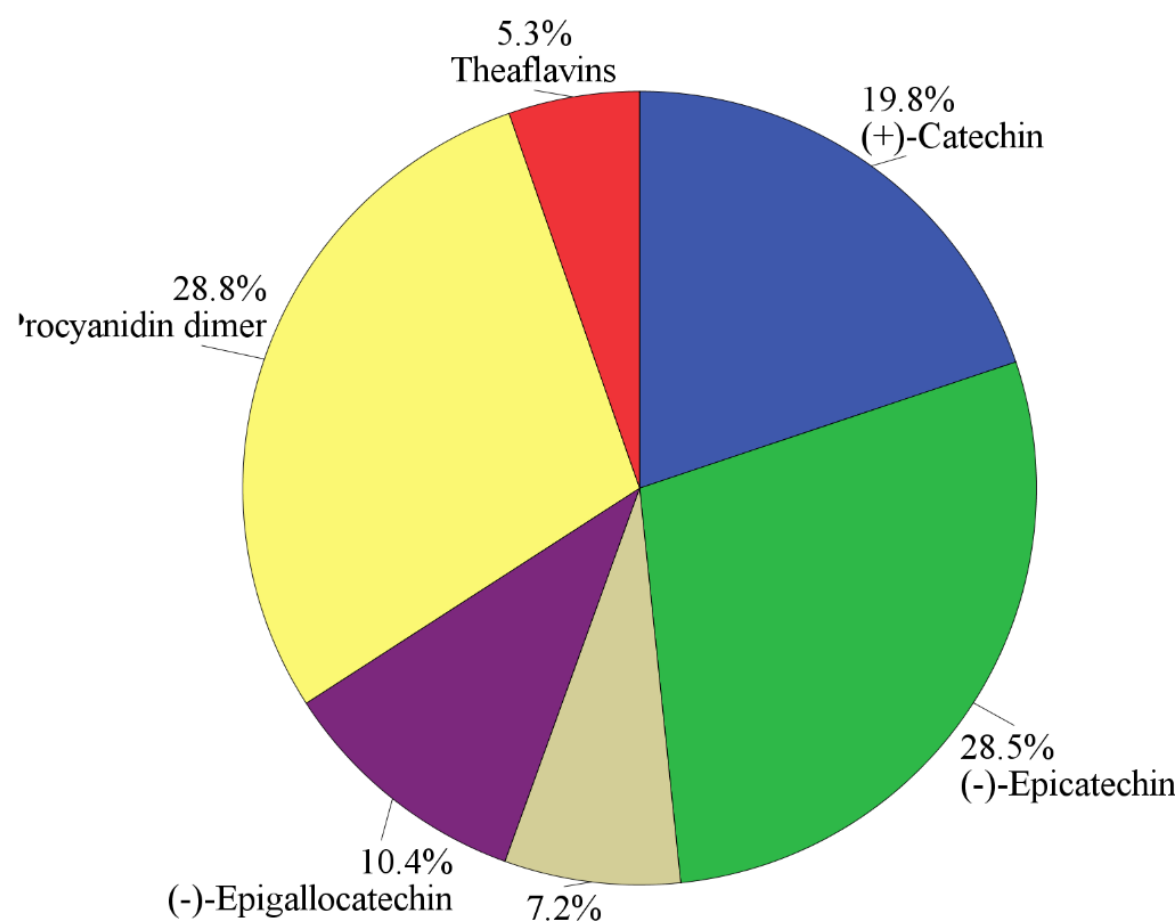

(+)-Gallocatechin
F) isoflavones

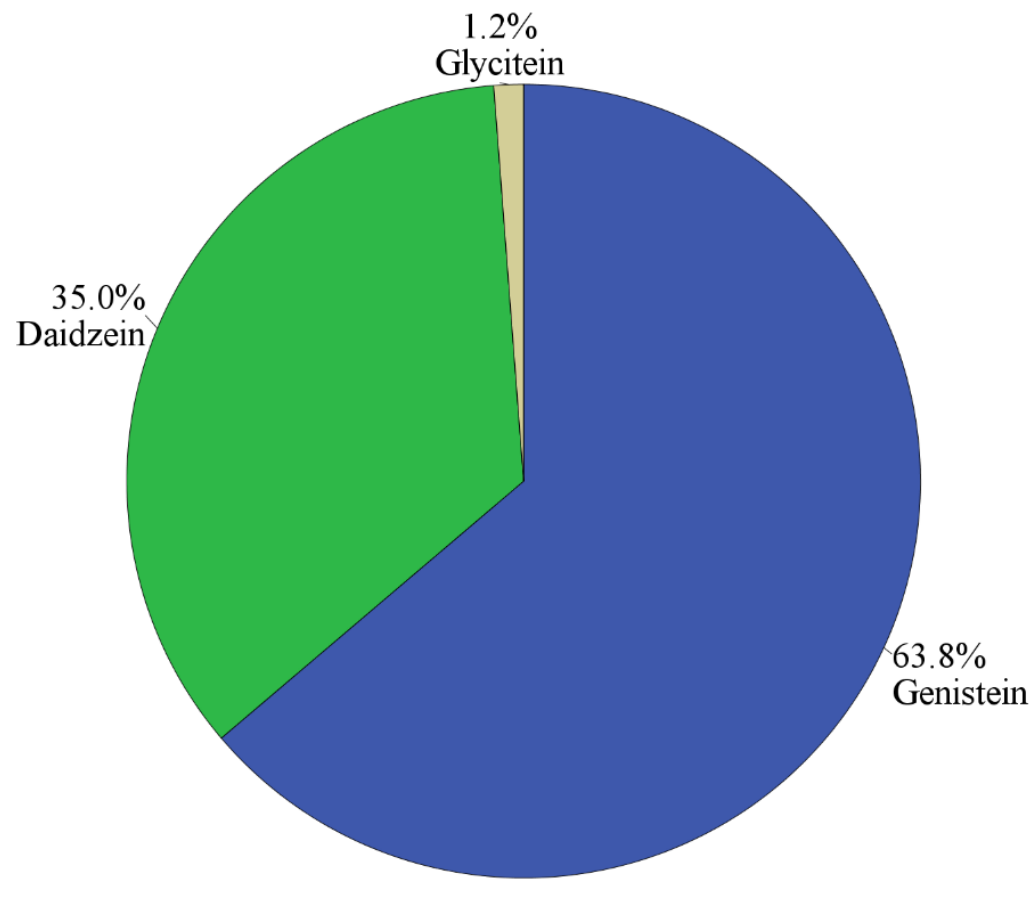

Figure 2 Percentage Contribution of Individual Flavonoids to Flavonoid Subclasses at 14 years for a) anthocyanins, b) flavonols, c) flavanones d) flavones e) flavan-3-ols and f) isoflavones 


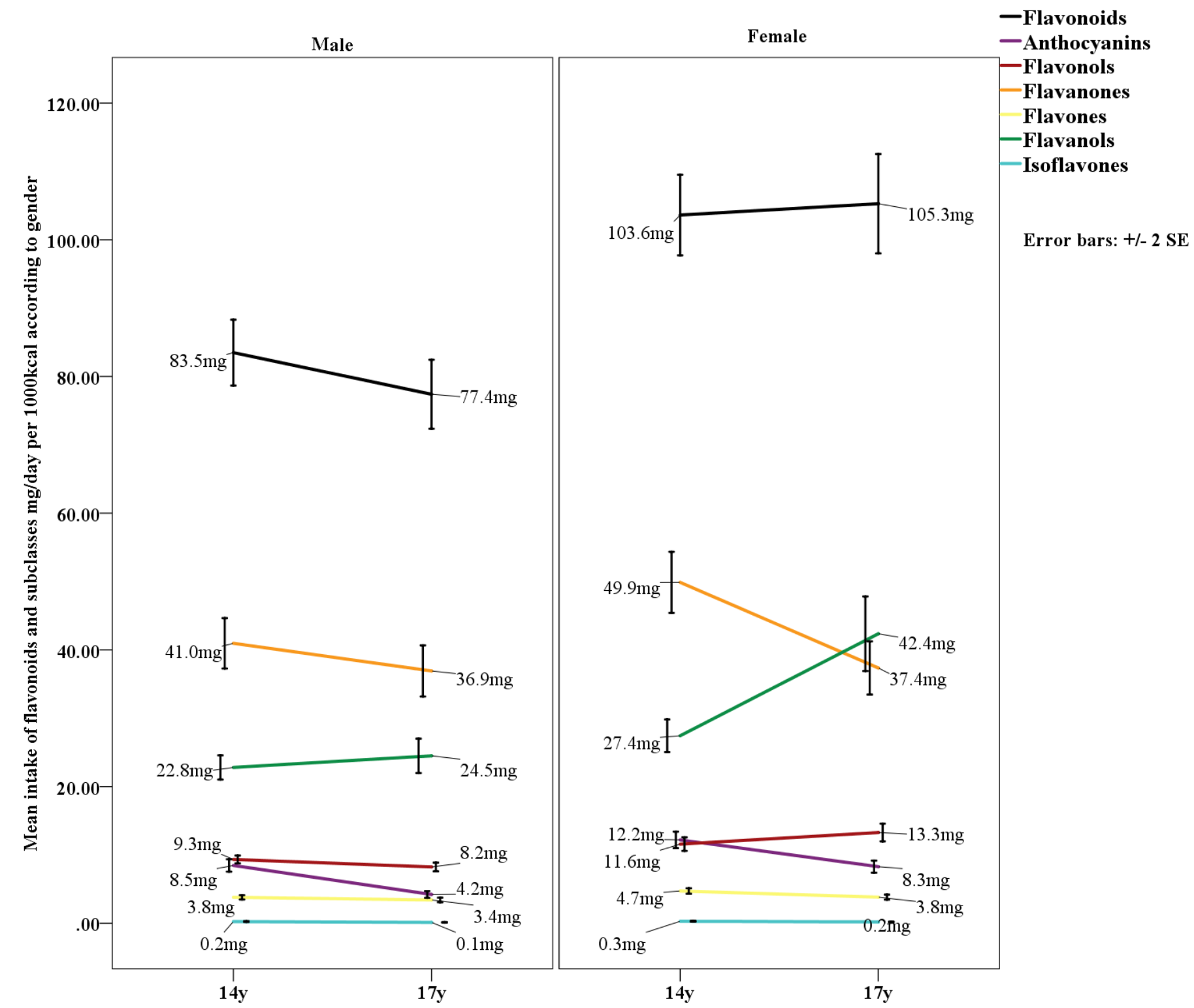

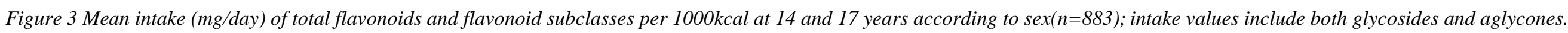


A)

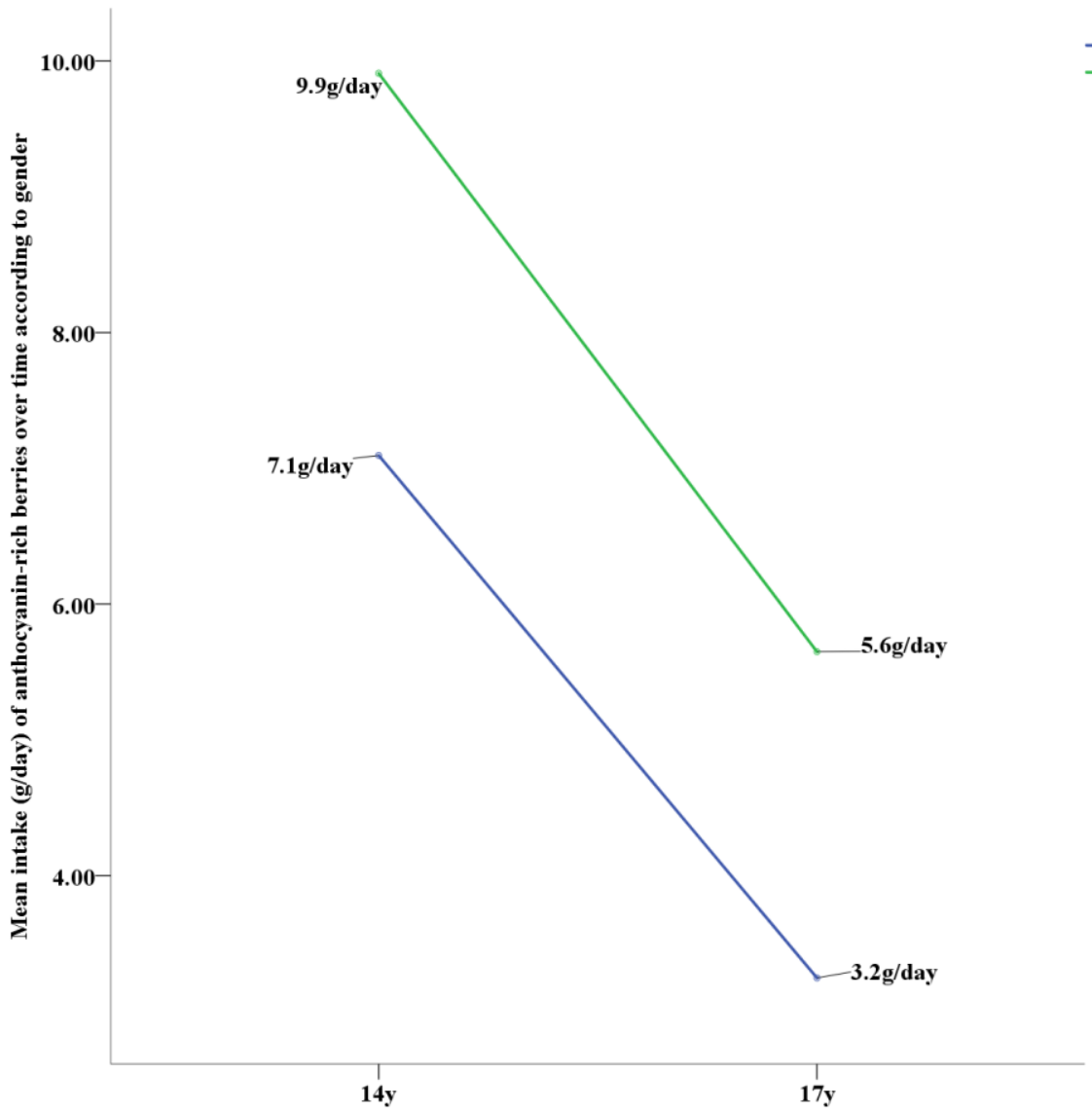

B)

- Male

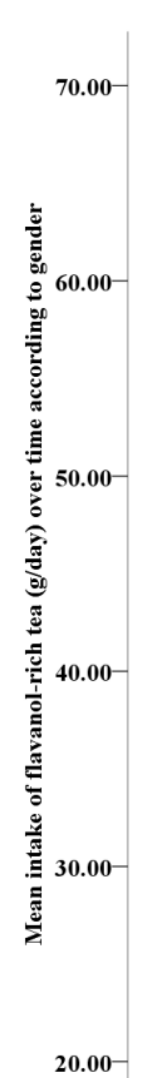

-Male

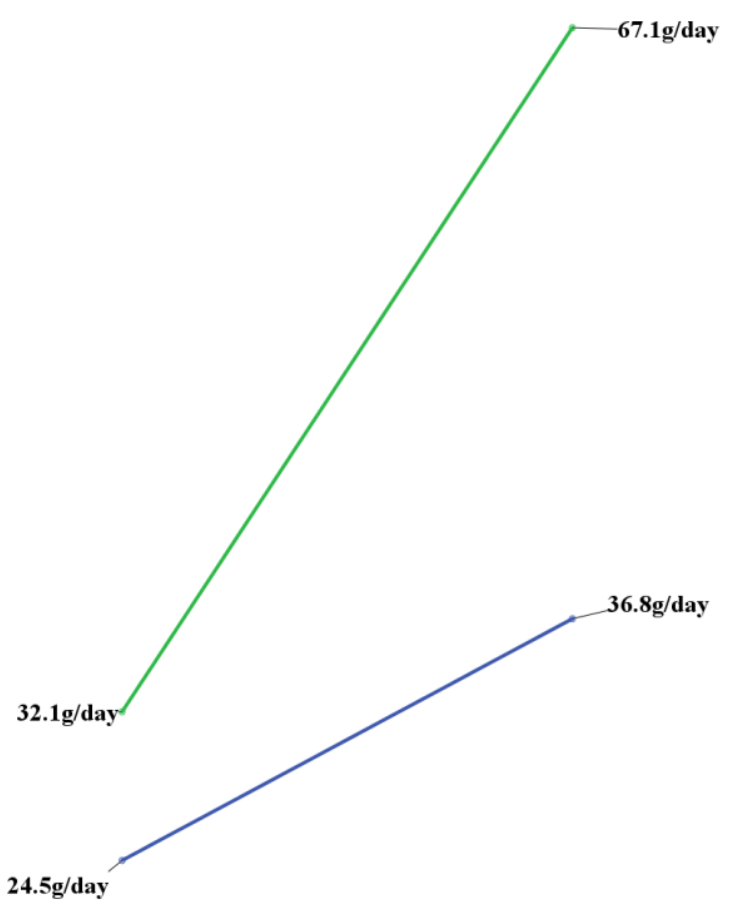

- Female 


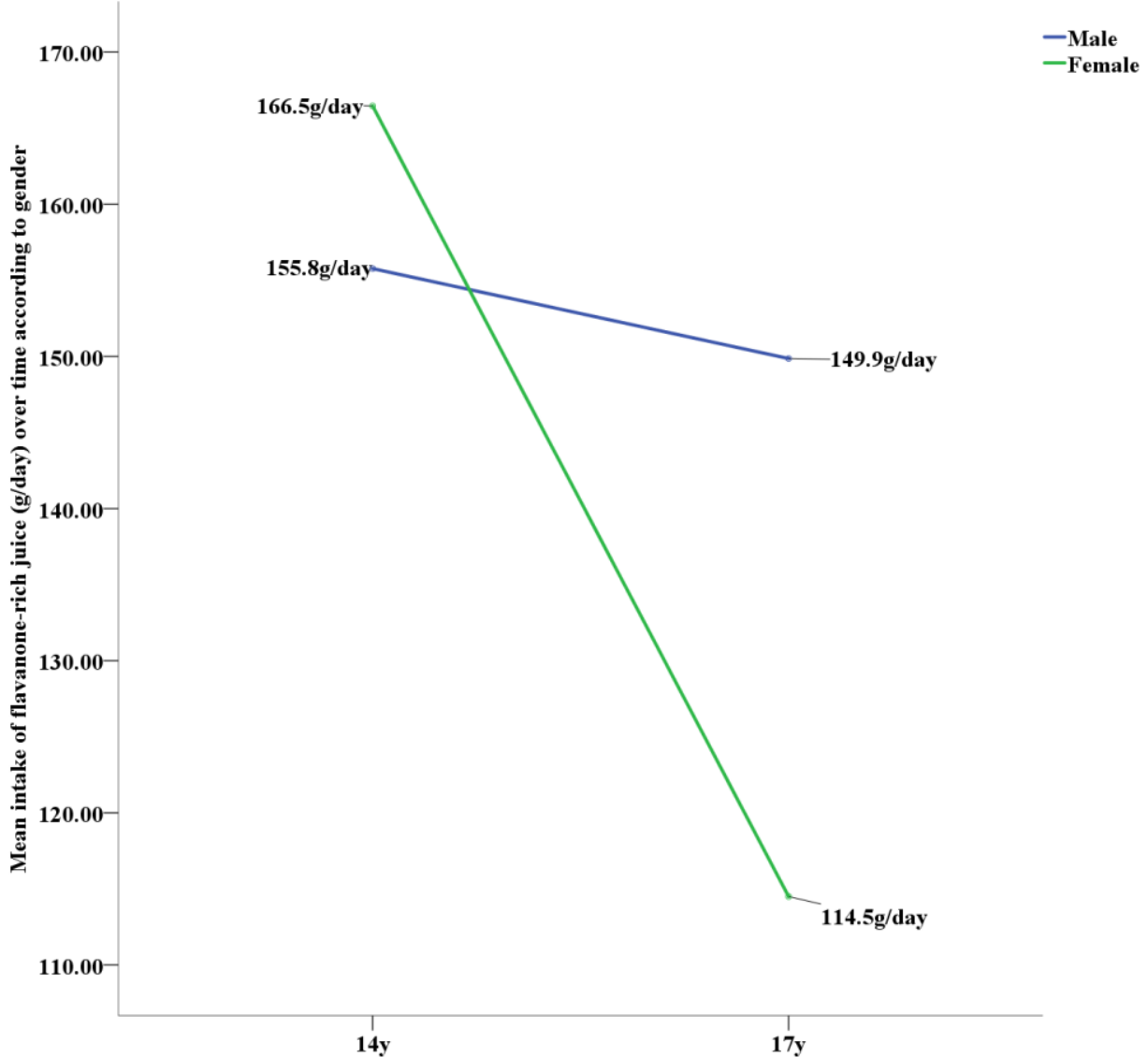

Figure 4 Change in mean intake of anthocyanin-rich berries (a), flavan-3-ol-rich tea (b) and flavanone-rich fruit juice (c) (grams/day) at 14 and 17 years according to sex 
1. Straker L, Mountain J, Jacques A, White S, Smith A, Landau L, et al. Cohort Profile: The Western Australian Pregnancy Cohort (Raine) Study-Generation 2. International Journal of Epidemiology. 2017;46(5):1384-5j. 